\title{
Risiko for spontanabort blant norske, førstegangsfødende tannleger
}

\author{
Jon E. Dahl ${ }^{1}$ og Johanne Sundby ${ }^{2}$ \\ ${ }^{1}$ NIOM, Nordisk institutt for odontologisk materialprøvning, Haslum \\ ${ }^{2}$ Seksjon for medisinsk antropologi, Institutt for almen- og samfunnsmedisinske fag, Universitetet i Oslo \\ Korrespondanse: Forsker Jon E. Dahl, NIOM, Nordisk institutt for odontologisk materialprøvning, Postboks 70, 1305 Haslum \\ Telefon: 67512200 telefax: 67591530 e-post: jon.dahl@niom.no
}

\begin{abstract}
SAMMENDRAG
Det er usikkerhet om eksponering for stoffer fra tannfyllingsmaterialer kan påvirke kvinners fertilitet. Vi har undersøkt forekomst av og risiko for spontanabort i første svangerskap blant praktiserende tannleger og sammenlignet resultatene med yrkesaktive lektorer/adjunkter og hjemmeværende kvinner. Et spørreskjema som omfattet en reproduktiv og en yrkesrelatert historie, ble sendt til alle kvinnelige medlemmer av Den norske tannlegeforening og et tilfeldig trukket utvalg av kvinnelige medlemmer i Norsk undervisningsforbund. Ved at ikke alle kvinnene var yrkesaktive i tiden før de ble gravide, kunne studiepopulasjonen deles i praktiserende tannleger $(\mathrm{n}=727)$, yrkesaktive lektorer/adjunkter $(\mathrm{n}=340)$ og hjemmeværende $(\mathrm{n}=300)$.

For studiepopulasjonen samlet spontanaborterte ca. ni prosent av alle kvinner i første svangerskap, og over tiårsintervallene fra 1951 til 1990 øte spontanabortfrekvensen fra 5,3\% til 11,5\%. Det var en signifikant sammenheng mellom graviditetsutfall og tid til graviditet. Kvinner som hadde brukt ni måneder eller mer på å bli gravide, spontanaborterte to ganger hyppigere enn dem som brukte kortere tid.

Risikoen for spontanabort blant praktiserende tannleger totalt var den samme som for hjemmeværende og for undervisningspersonell. I aldersgruppen over 30 år hadde tannlegene imidlertid 2,4 ganger høyere odds ratio (95\% konfidensintervall: 1.0-5.4) enn undervisningspersonell. Antatt eksponering for kvikksølv fra innlegging av amalgamfyllinger, for bensenholdig desinfeksjonssprit og for andre løsemidler økte ikke risikoen.
\end{abstract}

Dahl JE, Sundby J. Risk for spontaneous abortion among primiparous dental surgeons in Norway. Nor J Epidemiol 1999; 9 (1): 51-55.

\section{ENGLISH SUMMARY}

Occupational exposure to potentially hazardous agents may increase the risk of spontaneous abortion. The present study addresses the frequency and risk for miscarriage among dental surgeons compared to those of high-school teachers and non-employed women. A self-administered postal questionnaire was mailed to all dental surgeons registered in the Norwegian Dental Association $(\mathrm{n}=1320)$, and to a random sample of high schools teachers $(\mathrm{n}=1084)$, recruited from the registry in the Norwegian Educational Association. The data were collected retrospectively comprising the reproductive and occupational history of the female. The occupational exposure was addressed by a thorough examination of the work performed in the time when the couple tried to conceive and the woman became pregnant for her first time. The use of mercury containing dental amalgam, chloroform based root canal sealer, ethanol based disinfectant containing benzene, and other organic solvents was addressed in detail. Nitrous oxide sedation had not been used in dental surgeries in Norway when the survey was undertaken. The study was approved by the National Committee for Research Ethics and the Data Inspectorate in Norway.

As not all women were working at the time when they became pregnant, the study population was subdivided into dental surgeons $(n=727)$, high-school teachers $(n=340)$ and group of homemaking women $(n=300)$. On the average, $9.2 \%$ of the primiparous women had a spontaneous abortion. In the time period 1951-1990, the incidence of miscarriage increased from $5.3 \%$ to $11.5 \%$ for the study population. There was a significant correlation between outcome of pregnancy and time to pregnancy. Spontaneous abortion occurred twice as often in women who had a waiting time to pregnancy of nine months or more compared to women having shorter waiting time.

The risk for spontaneous abortion among practising dentists in total was the same as for homemakers and teachers. In the age group past 30 years the dentists had a 2.4 times higher odds ratio $(95 \%$ confidence interval: $1.0-5.4$ ) than teachers but it was not possible to link this to a specific occupational exposure. Exposure to mercury from the use of dental amalgam, to ethanol based disinfectant containing $0.25 \%$ benzene or to other solvents did not increase the risk. 


\section{INNLEDNING}

I forbindelse med debatten om bruk av amalgam som tannfyllingsmateriale er det blitt reist spørsmål om eksponering for kvikksølv utløst fra amalgamfyllinger kan øke risikoen for spontanabort. Norske helsemyndigheter har vurdert tannfyllingsmaterialer generelt (1). De anbefaler at det bør utvises tilbakeholdenhet med omfattende bruk av slike materialer på gravide fordi det hersker usikkerhet om eventuelle bivirkninger (1). Dersom tannfyllingsmaterialer skulle ha negative helseeffekter, er det trolig tannhelsepersonellet som løper den største risikoen. De kan eksponeres for helsefarlige stoffer fra fyllingsmaterialene under selve tannbehandlingen og før fyllingene herder. Hos tannhelsepersonell er det funnet sammenheng mellom arbeid med amalgam og kvikksølvnivået $i$ urin (2). I en studie av tannleger i Storbritannia ble det observert $ø$ kt risiko for spontanabort (3), men dette ikke kunne verifiseres i en senere svensk studie (4). Det var ingen økning av spontanabort risikoen blant danske tannlegeassistenter (5) og heller ingen forskjell i risiko mellom tannlegeassistenter i USA gruppert som høyt eller lavt eksponert for kvikksølv (6). Det har heller ikke vært mulig å finne noen klar sammenheng mellom eksponering for uorganisk kvikksølv og økt risiko for spontanabort i andre yrker (7).

Vi har tidligere funnet at yrkesaktive tannleger og lektorer/adjunkter er mindre fertile enn hjemmeværende kvinner (8). Det var imidlertid ikke mulig å knytte noen spesiell form for yrkeseksponering til den reduserte fruktbarheten (9). I den delstudien som presenteres her, undersøker vi forekomst og risiko for spontanaborter blant tannleger sammenlignet med undervisningspersonell (lektorer/adjunkter) og hjemmeværende. Analysene baserer seg på data fra en spørreundersøkelse blant norske tannleger, lektorer og adjunkter (8).

\section{UTVALG OG METODER}

\section{Studiedesign}

Data ble innhentet retrospektivt med hjelp av spørreskjema. Spørreskjema var utformet etter et utkast til retningslinjer fra European Studies on Infertility and Subfertility og beskrevet i detalj tidligere (8). Den yrkesrelaterte eksponeringen var basert på en kartlegging av deltagernes ulike arbeidsoppgaver i perioden før hun ble gravid. Hvis mulig, ble tiden forut for første, andre og siste graviditet kartlagt. Datainnsamlingen ble gjennomført i løpet av 1991. Studien har godkjenning av Forskningsetisk komité og Datatilsynet.

\section{Deltagelse og utvalgskriterier}

Spørreskjema ble sendt til alle kvinnelige medlemmer i Den norske tannlegeforening (NTF; $n=1320$ ) og et tilfeldig trukket utvalg av kvinnelige medlemmer i
Norsk undervisningsforbund (NUFO; $n=1084$ ) (Medlemmer i NUFO er senere gått inn i Lærerforbundet). Effektiv responsrate var $65 \%$ for NTF-medlemmer og $70 \%$ for NUFO-medlemmer. Den delstudien som presenteres her, er basert på kvinner som har vært gravide minst én gang, men kun data fra første graviditet er inkludert i detalj. Kvinner som ble gravide til tross for bruk av prevensjon, og graviditeter som ble terminert med provosert abort, er ikke tatt med. Utvalget bestod av 728 medlemmer av NTF og 669 NUFOmedlemmer. Kvinnene var født mellom 1903 og 1967 (1903-30: 70 respondenter, 1931-40: 230, 1941-50: 509, 1951-60: 521 og 1961-67: 63 kvinner). Enkelte spørreskjema var ikke fullstendig utfylt, slik at antall svar på ulike spørsmål varierte noe.

\section{Effekt og eksponering}

Deltagerne fikk spørsmål om deres fertilitet generelt, om første graviditet og om tiden forut for denne. Antall måneder med ubeskyttet samleie før kvinnen ble gravid, skulle angis. Svangerskap som endte før uke 24 ble definert som spontanabort. Tolv svangerskap endte med dødfødsel, og disse er ikke tatt med.

Eksponeringskartleggingen var basert på opplysninger om arbeidsoppgavene som deltageren anga å ha hatt i tiden før hun ble gravid, med spesiell vekt på de siste 6 månedene før svangerskapet oppsto. Antall lagte amalgamfyllinger per uke var mål på kvikksølveksponeringen. Bruksfrekvensen av desinfeksjonsmidler og løsemidler indikerte eksponeringen for disse stoffene. Eksponering for kloroform var basert på antall utførte rotfyllinger med kloroformholdig forseglingsmateriale. Lystgass var ikke i bruk på norske tannklinikker i den tiden som omfattes av undersøkelsen, og ble derfor ikke tatt med. Ved at en del kvinner organisert i NUFO ikke var yrkesaktive i tiden før graviditeten, kunne man lage en tredeling av utvalget i praktiserende tannleger, yrkesutøvende lektorer/adjunkter og hjemmeværende.

\section{Analyser}

Spontanabortfrekvensen ble bestemt med krysstabulering og Cochran-Mantel-Haenzel statistikk (FREQ procedure, SAS $/ \mathrm{STAT}^{\mathbb{B}}$ ) og spontanabortrisiko med logistisk regresjon (LOGISTIC procedure, SAS $/$ STAT $^{\mathbb{B}}$ ). Forskjeller i tid til graviditet ble bestemt med overlevelsesanalyse (LIFETEST procedure, $\mathrm{SAS} / \mathrm{STAT}^{\mathbb{B}}$ ). Odds ratio estimater tjente som en approksimering av relativ risiko, selv om det kan gi en overestimering av risiko i de tilfeller der abortfrekvensen er høy.

\section{RESULTATER}

Fordelingen av antall spontanaborter blant medlemmene $\mathrm{i}$ de to yrkesorganisasjonene er gitt $\mathrm{i}$ Tabell 1. Første graviditet endte med spontan abort blant $6,7-19 \%$ av kvinnene i de ulike yrkes- og alders- 
grupper av utvalget (Tabell 2). Det var en klar økning i spontanabortfrekvensen gjennom tiårsintervallene fra 1951 til 1990 (Tabell 2). Tabell 3 viser estimater for spontanabortrisiko i ulike undergrupper av utvalget. Samlet sett var risikoen blant praktiserende tannleger og undervisningspersonell den samme som for hjemmeværende. Tannleger over 30 år hadde 2,4 ganger høyere odds ratio for spontanabort (95\% konfidensintervall: 1.0-5.4) enn undervisningspersonell over 30 år. Sammenligninger med hjemmeværende over 30 år var ikke mulig fordi denne gruppen var liten $(n=9)$ og uten spontanaborter. Antatt eksponering for kvikksølv fra innlegging av amalgamfyllinger, for bensenholdig desinfeksjonssprit og for andre løsemidler økte ikke risikoen for spontanabort. Da antallet tannleger som ukentlig utførte rotfyllinger med kloroformholdig forseglingsmateriale, var lite $(n=38)$, ble risiko for spontanabort ved kloroformeksponering ikke beregnet.

Det var en klar samvariasjon mellom graviditetsutfall og tid til graviditet også i aldersgruppen under 30 år (Figur 1). Kvinner som hadde brukt ni måneder eller mer på å bli gravide, aborterte to ganger hyppigere enn dem som hadde brukt kortere tid (Tabell 4). Hver syvende kvinne under 30 år som hadde brukt ni måneder eller mer på å bli gravid, aborterte, og hver femte i aldersgruppen 30 år og eldre. Samvariasjonen var også entydig over ulike tiårsstrata for graviditetstidspunkt.

Tabell 1. Frekvensfordeling av spontanaborter blant alle respondenter. NTF $=$ medlemmer av Den norske tannlegeforening. NUFO = medlemmer av Norsk undervisningsforbund. p-verdi for forskjell mellom gruppene er 0,16 .

\begin{tabular}{ccc}
\hline Antall & NTF $(\mathrm{n}=728)$ & NUFO $(\mathrm{n}=669)$ \\
\hline ingen & $77,9 \%$ & $80,2 \%$ \\
1 & $16,1 \%$ & $14,7 \%$ \\
2 & $3,0 \%$ & $3,4 \%$ \\
3 & $1,4 \%$ & $1,0 \%$ \\
4 & $0,3 \%$ & $0,4 \%$ \\
5 & $0 \%$ & $0,2 \%$ \\
\hline
\end{tabular}

Tabell 2. Sponabortfrekvens i første graviditet i relasjon til yrkesutførelse i tiden før kvinnen ble gravid samlet og fordelt på tiårs intervaller. Spontanabortfrekvensen er beregnet ut fra totalt antall graviditeter i hver undergruppe, og antallet aborter er gitt $\mathrm{i}$ parentes. $\mathrm{n}=$ antall respondenter. Ikke alle kvinner hadde angitt $\mathrm{i}$ hvilket år hun ble gravid. Kvinner som ble gravide til tross for bruk av prevensjon, og graviditeter som endte med provosert abort er unntatt $\mathrm{i}$ beregningen.

\begin{tabular}{|c|c|c|c|c|c|c|c|c|c|c|}
\hline \multirow[b]{2}{*}{ Tannlege, $<30$ år } & \multirow{2}{*}{$\frac{\mathrm{n}}{607}$} & \multicolumn{2}{|c|}{ Alle år } & \multicolumn{2}{|c|}{$\begin{array}{l}1951-60 \\
(n=150)\end{array}$} & $\begin{array}{l}1961-70 \\
(n=355)\end{array}$ & \multicolumn{2}{|c|}{$\begin{array}{l}1971-80 \\
(\mathrm{n}=351)\end{array}$} & \multicolumn{2}{|c|}{$\begin{array}{l}1981-90 \\
(\mathrm{n}=375)\end{array}$} \\
\hline & & $7,3 \%$ & (44) & $3,9 \%$ & (3) & $4,2 \% \quad(6)$ & $5,1 \%$ & (10) & $8,1 \%$ & (14) \\
\hline Tannlege, $\geq 30$ år & 120 & $19,0 \%$ & (23) & $14,3 \%$ & (2) & $7,1 \% \quad(1)$ & $11,1 \%$ & (3) & $26,2 \%$ & $(17)$ \\
\hline Undervisning, $<30$ år & 247 & $11,7 \%$ & (29) & $8,0 \%$ & (2) & $8,1 \% \quad(6)$ & $12,4 \%$ & (11) & $10,9 \%$ & (6) \\
\hline Undervisning, $\geq 30$ år & 93 & $10,8 \%$ & $(10)$ & $0 \%$ & (0) & $16,7 \% \quad(2)$ & $9,4 \%$ & (3) & $10,6 \%$ & (5) \\
\hline Hjemmeværende, $<30$ år & 291 & $6,7 \%$ & (19) & $3,2 \%$ & (1) & $5,4 \% \quad(6)$ & $7,8 \%$ & (8) & $3,1 \%$ & (1) \\
\hline Hjemmeværende, $\geq 30$ år & 9 & $0 \%$ & (0) & $0 \%$ & (0) & $0 \% \quad(0)$ & $0 \%$ & (0) & $0 \%$ & $(0)$ \\
\hline Samlet & 1367 & $9,1 \%$ & (125) & $5,3 \%$ & (8) & $5,9 \%(21)$ & $10,0 \%$ & (35) & $11,5 \%$ & $(43)$ \\
\hline
\end{tabular}

Tabell 3. Risiko for spontanabort ved første graviditet. Verdiene er justert for alder, røyking, tid til graviditet og det tiår da kvinnen var gravid. $95 \% \mathrm{KI}=95 \%$ konfidensintervall.

\begin{tabular}{lccl}
\hline Aktivitet & Odds ratio & $95 \%$ KI & Referansegruppe \\
\hline $\begin{array}{l}\text { Praktisere som tannlege }(\mathrm{n}=727) \\
\text { Praktisere som tannlege }(\mathrm{n}=727)\end{array}$ & 1,0 & $0,7-1,4$ & $\begin{array}{l}\text { Hjemmeværende }(\mathrm{n}=291) \\
\text { Undervise på skole }(\mathrm{n}=340)\end{array}$ \\
$\begin{array}{l}\text { Praktisere som tannlege, } \\
\text { alder over 30 år }(\mathrm{n}=120)\end{array}$ & 2,4 & $1,0-5,4$ & $\begin{array}{l}\text { Undervise på skole, } \\
\text { alder over 30 år }(\mathrm{n}=93)\end{array}$ \\
$\begin{array}{l}\text { Legge }>50 \text { amalgam/uke }(\mathrm{n}=249) \\
\text { Ingen yrkesmessig eksponering }\end{array}$ & 0,7 & $0,4-1,3$ & $\begin{array}{l}\text { Ingr amalgam (n=466) } \\
\text { for }\end{array}$ \\
$\begin{array}{l}\text { Daglig eksponering for } \\
\text { desinfeksjonssprit }(\mathrm{n}=301)\end{array}$ & 0,8 & $0,4-1,6$ & $\begin{array}{l}\text { Ingen yrkesmessig eksponering } \\
\text { for desinfeksjonssprit }(\mathrm{n}=639)\end{array}$ \\
$\begin{array}{l}\text { Minst ukentlig eksponering for } \\
\text { andre løsemiddel }(\mathrm{n}=149)\end{array}$ & 0,8 & $0,3-1,5$ & $\begin{array}{l}\text { Ingen yrkesmessig eksponering } \\
\text { for løsemiddel }(\mathrm{n}=636) \\
\text { Undervise på skole }(\mathrm{n}=340)\end{array}$ \\
\hline
\end{tabular}




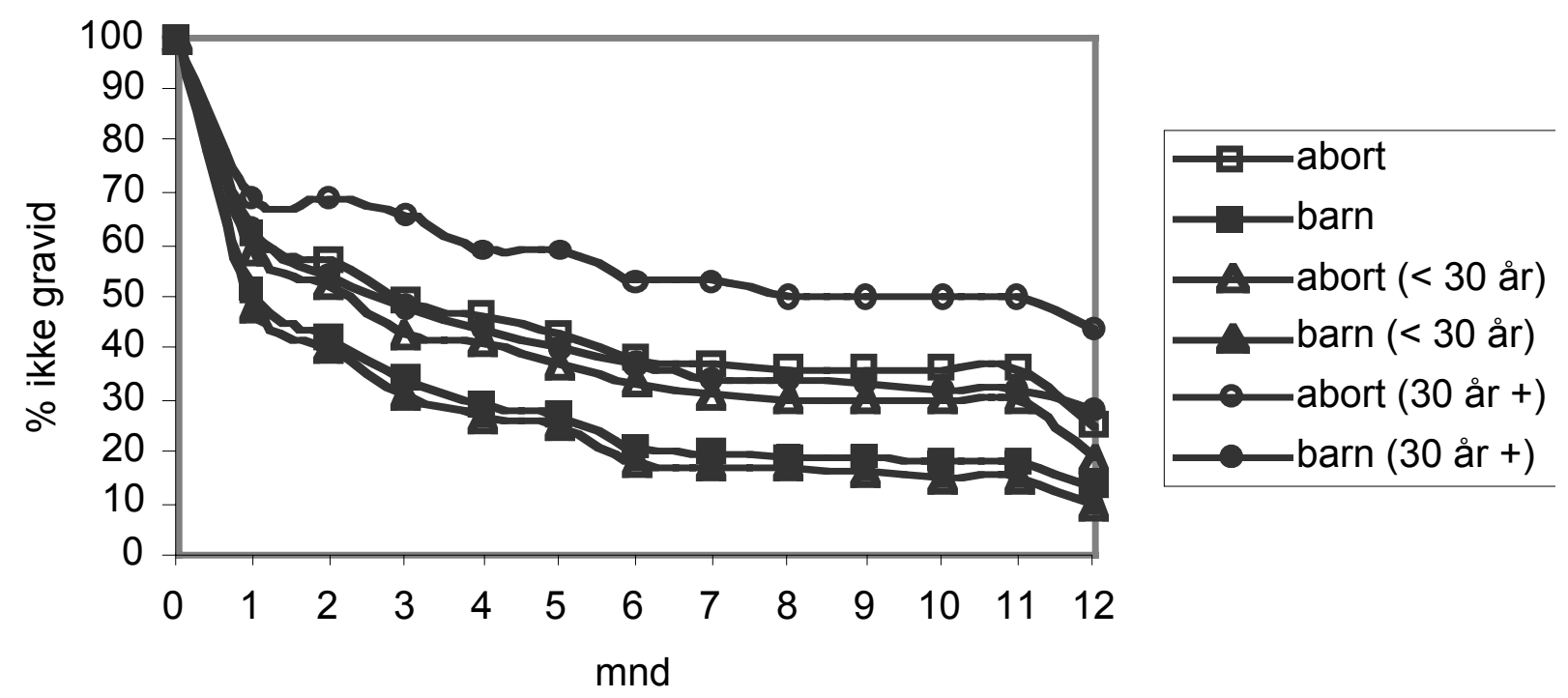

Figur 1. Tid til graviditet for svangerskap som endte med spontan abort (abort), levende født barn (barn) for hele utvalget, for aldersgruppen under 30 år [spontan abort (abort $<30$ år), levende født barn (barn $<30$ år)] og for aldergruppen 30 år og eldre [spontan abort (abort 30 år +), levende født barn (barn 30 år +)].

Tabell 4. Tid til graviditet i relasjon til spontan abort og levende født barn som graviditetsutfall. Data fra tannleger, undervisning og hjemmeværende er slått sammen.

\begin{tabular}{lcc}
\hline & \multicolumn{2}{c}{ Graviditetsutfall } \\
\cline { 2 - 3 } Tid til graviditet (TTG) & Spontan abort & Levende barn \\
\hline Hele utvalget & & \\
TTG $<9$ mnd & 84 & 1019 \\
TTG $\geq 9$ mnd & 42 & 218 \\
Alder under 30 år & & \\
TTG $<9$ mnd & 61 & 812 \\
TTG $\geq 9$ mnd & 23 & 145 \\
Alder 30 år og mer & & \\
TTG $<9$ mnd & 23 & 207 \\
TTG $\geq 9$ mnd & 19 & 73 \\
\hline
\end{tabular}

\section{DISKUSJON}

Spontanabortfrekevensen blant yrkesaktive kvinner er tidligere funnet å være mellom $6,6 \%$ og $13,4 \%$ (7). Med unntak for tannleger over 30 år er funnene $i$ denne studiepopulasjonen tilsvarende. Imidlertid sees en klar økning av spontanabortfrekvensen i de fire tiårsintervallene fra 1951 til 1990, selv om det kan være mer underrapportering i de tidligste tiårene ved at kvinnen etter hvert har fortrengt eller glemt en graviditet som endte med abort. Det var relativt stor variasjon mellom ulike undergrupper av utvalget, men siden enkelte av undergruppene var små, ble resultatene usikre.
Tannleger generelt løp samme risiko for å spontanabortere som hjemmeværende kvinner og undervisningspersonell. Tannleger over 30 år aborterte dobbelt så ofte i første svangerskap som sine jevnaldrende adjunkter/lektorer. Selv om forklaringene høyst sannsynlig kan være yrkesbetinget eller av biologisk karakter, var det ikke mulig å knytte dette til noen spesifikk eksponeringssituasjon eller til andre risikofaktorer i denne undersøkelsen.

Antall lagte amalgamfyllinger er en brukbar indikator for kvikksølveksponering blant tannhelsepersonellet (2). Mens bruken av amalgam er sterkt redusert i løpet av den perioden som omfattes av denne undersøkelsen (9), er spontanabort frekevensen spesielt hos yngre tannleger øket. Det skulle indikere en manglende relasjon mellom kvikksølveksponering og spontanabort. Vi fant heller ikke noen økt risiko for spontanaborter blant kvinner som la mer enn 50 amalgamfyllinger per uke sammenlignet med dem som ikke la slike fyllinger. Disse funn stemmer overens med resultater fra andre studier av abortrisiko hos kvinner som er yrkesmessig eksponert for kvikksølv $(10,11)$.

Eksponering for bensenholdig desinfeksjonssprit $(0,25 \%$ benzen) økte heller ikke risikoen for spontanaborter. Bensen er teratogent (12), men eksponeringsnivåene ved bruk av desinfeksjonssprit til overflate- og annen desinfeksjon, var sannsynligvis for lave til å gi effekter. Vi fant heller ikke benseninduserte effekter på fertiliteten målt som tid til graviditet (9).

Det var ikke forskjell i spontanabortrisikoen mellom lektorer/adjunkter og hjemmeværende samlet sett. 
Det er i samsvar med tidligere studier hvor det heller ikke ble funnet økt risiko for spontanaborter blant undervisningspersonell $(13,14)$.

Vi fant en entydig samvariasjon mellom forlenget tid til graviditet og spontanabortfrekvens, også blant yngre kvinner. Tidligere analyser av studiepopulasjonen har vist at kvinner over 30 år var mindre fertile enn dem som var yngre; dvs. de eldste brukte lenger tid på å bli gravide (8), og denne studien har vist at de også har en større risiko for å abortere. Men også yngre kvinner med forlenget tid til graviditet hadde økt sjanse for å abortere når kvinnen først ble gravid. En slik samvariasjon har oss bekjent ikke vært vist tidligere, selv om den ikke var overraskende. Økt tid til graviditet kan være en manifestasjon på en førklinisk abort slik at de to parameterne kan være uttrykk for den samme biologiske respons, men til ulike tidspunkter. Redusert evne til konsepsjon er en annen årsak til forlenget tid til graviditet. I dette tilfelle kan biologiske faktorer, f.eks. hormonell dysfunksjon, hos kvinnen forklare sammenhengen med økt risiko for spontanabort. Andre faktorer som spiller en rolle for kvinners evne til å føde et levende barn, er mannens biologiske fertilitet og muligheten for å ha samleie på ovulasjonstidspunktet. En annen mulig hypotese kan være at psykogene belastninger hos kvinner med lang ventetid til graviditet påvirker aborthyppigheten. I litteraturen om psykogene årsaker til infertilitet er det ingen gode studier som demonstrerer at det faktisk er en slik sammenheng, men det er snarere slik at et ugunstig reproduktivt utfall påvirker den psykiske helsen (15).

Våre funn kan også kaste lys over det forhold at abortfrekvensen ved assistert befruktning synes å være høyere enn ved naturlig befruktning (16). I utgangspunktet er det lavfertile kvinner eller par som søker slik behandling, og disse kvinnene er nå vist også å ha økt risiko for å abortere om de blir gravide.

\section{REFERANSER}

1. Statens helsetilsyn. Statens helsetilsyns vurderinger og anbefalinger. Bruk av tannrestaureringsmaterialer i Norge. Oslo: Statens helsetilsyn 1998: 7-20.

2. Jokstad A. Mercury excretion and occupational exposure of dental personnel. Community Dent Oral Epidemiol 1990; 18: 143-8.

3. Nixon GS, Helsby CA, Gordon H, Hytten FE, Renson CE. Pregnancy outcome in female dentists. Br Dent $J$ 1979; 146: 39-42.

4. Ericson A, Källén B. Pregnancy outcome in women working as dentists, dental assistants or dental technicians. Int Arch Occup Environ Health 1989; 61: 329-33.

5. Heidam LZ. Spontaneous abortions among dental assistants, factory workers, painters, and gardening workers: a follow up study. J Epidemiol Community Health 1984; 38: 149-55.

6. Brodsky JB, Cohen EN, Whicher C, Brown BW Jr, Wu ML. Occupational exposure to mercury and pregnancy outcome. J Am Dent Assoc 1985; 111: 779-80.

7. Antilla A, Sallmén M. Effects of parental occupational exposure to lead and other metals on spontaneous abortion. J Occup Environ Med 1995; 37: 915-21.

8. Sundby J, Dahl JE. Are women in the workplace less fertile than women who are not employed? $J$ Women's Health 1994; 3: 65-72.

9. Dahl JE, Sundby J, Hensten-Pettersen A, Jacobsen N. Dental workplace exposure and effect on fertility. Scand J Work Environ Health 1999 (in press).

10. De Rosis F, Anastasio SP, Selvaggi L, Betrame A, Moriani G. Female reproductive health in two lamp factories: effects of exposure to inorganic mercury vapour and stress factors. Br J Ind Med 1985; 42: 488-94.

11. Elghany NA, Stopford W, Bunn WB, Flemming LE. Occupational exposure to inorganic mercury vapour and reproductive outcome. Occup Med 1997; 47: 333-6.

12. Benzene. Environmental Health Criteria 150. Geneva: World Health Organization, 1993.

13. Ahlborg G, Hogstedt C, Bodin L, Bárány S. Pregnancy outcome among working women. Scand J Work Environ Health 1989; 15: 227-33.

14. Savitz DA, Olshan AF, Gallagher K. Maternal occupation and pregnancy outcome. Epidemiology 1996; 7: 269-74.

15. Sundby J. Infertility - causes, care and consequences. Thesis. Oslo: University of Oslo, 1994; 95 pp.

16. Kahn JA, Sunde A, Düring V, Sørdal T, Eriksson N, Molne K. In vito fertilisering - hvor stor andel av parene får barn? Tidsskr Nor Laegeforen 1993; 113: 932-5. 